\title{
Numerical solution of the thermal problem for electric heating of concrete structures in winter
}

\author{
Aleksei Gnyrya, Sergey Korobkov ${ }^{*}$, and Ivan Gaag \\ Tomsk State University of Architecture and Building, 634003, Tomsk, Russia
}

\begin{abstract}
This paper presents the results of a numerical solution of the thermal problem for electrical heating of a monolithic reinforced concrete raft foundation in the ELCUT Pro software and computing system. The purpose of this work was to solve a thermodynamic problem in the case of electric heating of concrete of a monolithic raft foundation with insulated heating wires in the winter. The foundations of an industrial building under construction in Tomsk are taken as a basis. The relevance of these studies in construction is caused by the need to ensure the temperature conditions necessary for the hardening and strength of concrete in the winter. The initial parameters for the concrete structure being built were entered in the Elcut Pro software package with the WinConcret add-in. As a result of the calculation, the optimal step of winding insulated heating wires on the reinforcing cage was determined, which leads to a uniform distribution of temperature fields over the section of the structure. The analysis of the temperature field in the section of the structure was carried out. Technological measures were developed that level this field and at the same time ensure a favorable temperature of concrete hardening, which is the main task of thermal calculation. Based on the simulation results obtained in the Elcut Pro software package, a technology has been developed for electric heating of concrete foundations at negative temperatures, which has been implemented in the conditions of a construction site.
\end{abstract}

\section{Introduction}

In Russia, concrete work on a construction site is carried out both in summer and in winter. An urgent problem in construction is to ensure the temperature conditions necessary for hardening and building strength of concrete in winter. When concreting in winter, the concrete needs heat treatment - heating. At low temperatures, reinforced concrete monolithic structures are heated by various methods. One of the methods of winter concreting is a method with the use of insulated heating wires, the essence of which is conductive heat transfer in the contact zone of concrete from a heated wire in the body of a heated structure and further heat distribution over its cross section due to thermal conductivity [1-10]. Since the correct mode of heat treatment of concrete significantly affects the strength of the structure, the preliminary calculation of the temperature and its

\footnotetext{
*Corresponding author: korobkov_1973@mail.ru
} 
subsequent control during concreting are important components of winter concreting [1112].

Therefore, a preliminary calculation of the curing temperature is a necessary condition for obtaining a high-quality monolithic structure.

However, manual calculations according to existing methods give approximate results, since the calculation process does not take into account many factors in the methods of curing concrete during winter concreting.

As a result, all the approximations and simplifications do not give an integral picture of the temperature curing of concrete in winter, and do not give an idea of the distribution of temperature fields, the nature of changing temperature of the structure in time [11].

This problem can be solved by modeling thermal fields based on the finite element method (FEM) in a modern software and computing complex Elcut Pro 6.3 (license agreement dated June 26, 2018 with the developer OOO "Tor", St. Petersburg) [13].

Nowadays, many Russian scholars are engaged in the formulation and implementation of methods for the numerical solution of the thermal problem during heat treatment of concrete [11, 13-19].

The program contains the necessary modules for performing calculations for the curing of concrete - modules of alternating current, non-stationary thermal conductivity, elastic stresses and deformation. However, ELCUT doesn't have additional functions for calculations for the heating and curing of concrete, so it is equipped with the WinConcret add-in [20].

This program calculates the temperature fields in the section plane of the concreted structures, solving a stationary problem to determine the initial conditions, after which a number of non-stationary problems are solved with a given integration step and the construction of temperature fields.

In ELCUT, there is a choice of different sources of heat energy, materials and climatic conditions for winter concreting. Heat from cement hydration is taken into account in the WinConcret add-in.

The heat generation of the hydration reaction is given as a function of time and temperature. The solution to the problem is presented in the form of a set of diagrams depicting the temperature fields at different stages of heating. The program also builds graphs of temperature changes for individual sections of the structure and a graph of concrete strength gain $[13,19]$.

The purpose of this work was to solve a thermodynamic problem in the case of electric heating of concrete of a monolithic raft foundation with insulated heating wires in winter.

The modeling was carried out in several stages.

1) statement of the problem, formation of a computational model, setting properties, solving the original problem

2) clarifying calculation;

3) analysis of the results obtained.

\section{Materials and Methods}

A monolithic reinforced concrete raft foundation on a pile basis of an industrial building under construction in Tomsk was chosen as the structure under study. The dimensions of the foundation in the plan are $1.5 \times 1.5 \mathrm{~m}$, the height is $2.65 \mathrm{~m}$ (Fig. 1). The foundation is reinforced with steel meshes and flat frames. The foundation is concreted at an outside air temperature of $-15^{\circ} \mathrm{C}$. Heating is carried out using a PNSV-1.2 heating wire laid with an initial step of $200 \mathrm{~mm}$. Heat loss occurs through the side surfaces of the timber formwork. 


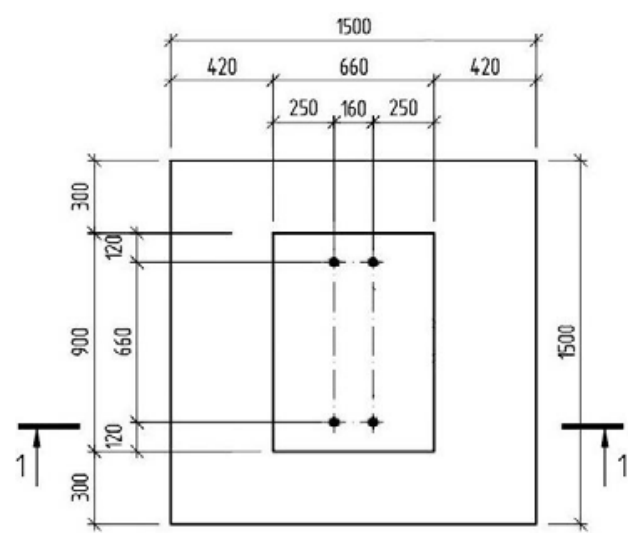

a)

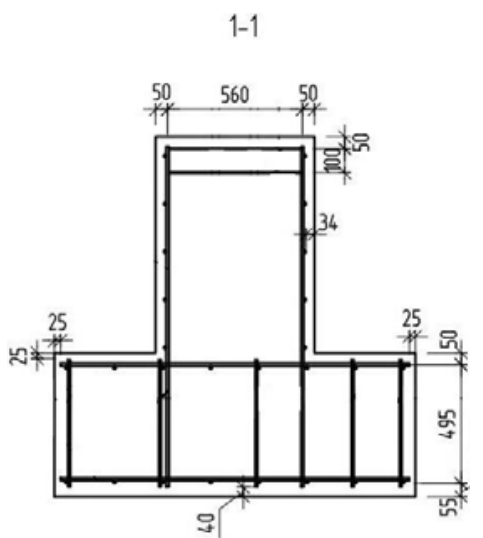

b)

Fig. 1. Monolithic reinforced concrete raft foundation: a) - in plan; b) - in section

Analysis of the temperature field in the section of the structure and the development of technological measures that level this field and at the same time provide a favorable temperature for concrete hardening is the main task of thermal calculation [20].

To solve this problem, within the framework of the study, a design model (DM) was created with the construction of a mesh of finite elements in the ELCUT software package in compliance with the geometric dimensions and mechanical properties of materials. The section of the foundation was modeled as a design scheme.

Figure 2 shows a design model with the construction of a finite element mesh, which has 56 blocks and 1484 mesh nodes.

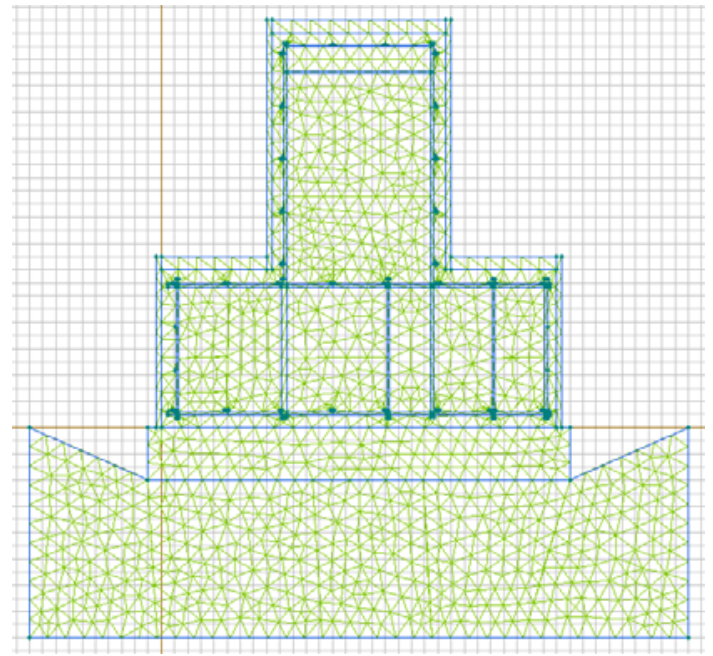

Fig. 2. Design model with the construction of the finite element mesh

In the design model, the following thermodynamic characteristics of materials and their physical parameters were applied.

Initial data - heavy concrete class B20, heat source - insulated heating wires, formwork $18 \mathrm{~mm}$ thick laminated plywood, insulation - $50 \mathrm{~mm}$ thick mineral slab, base - compacted fill soil, to create an "air gap" between the ground and the foundation, $200 \mathrm{~mm}$ thick foam was used. 
Initial conditions: initial temperature of the concrete mixture $-+10^{\circ} \mathrm{C}$, base temperature - minus $5^{\circ} \mathrm{C}$, soil temperature at a depth of $0.6 \mathrm{~m}$ - minus $2^{\circ} \mathrm{C}$, ambient temperature - minus $15^{\circ} \mathrm{C}$, wind speed $-4 \mathrm{~m} / \mathrm{s}$, operating voltage $-65 \mathrm{~V}$, the linear power of the heating wire is $40 \mathrm{~W} / \mathrm{m}$.

Material characteristics: reinforcement - thermal conductivity coefficient $-58 \mathrm{~W} /\left(\mathrm{m} \cdot{ }^{\circ} \mathrm{C}\right)$, specific heat capacity - $0.48 \mathrm{~kJ} /\left(\mathrm{kg} \cdot{ }^{\circ} \mathrm{C}\right)$, density - $7850 \mathrm{~kg} / \mathrm{m}^{3} ;$ concrete - thermal conductivity coefficient $-1.86 \mathrm{~W} /\left(\mathrm{m}^{\cdot{ }^{\circ}} \mathrm{C}\right)$, specific heat $-0.84 \mathrm{~kJ} /\left(\mathrm{kg} \cdot{ }^{\circ} \mathrm{C}\right)$, density -2400 $\mathrm{kg} / \mathrm{m}^{3}$; formwork - thermal conductivity coefficient $-0.17 \mathrm{~W} /\left(\mathrm{m} \cdot{ }^{\circ} \mathrm{C}\right)$, specific heat capacity - $2.52 \mathrm{~kJ} /\left(\mathrm{kg}{ }^{\circ} \mathrm{C}\right)$, density - $600 \mathrm{~kg} / \mathrm{m}^{3}$; mineral wool insulation - thermal conductivity coefficient $-0.049 \mathrm{~W} /\left(\mathrm{m} \cdot{ }^{\circ} \mathrm{C}\right)$, specific heat capacity $-0.76 \mathrm{~kJ} /\left(\mathrm{kg} \cdot{ }^{\circ} \mathrm{C}\right)$, density $-50 \mathrm{~kg} / \mathrm{m}^{3}$, foam - thermal conductivity coefficient $-0.037 \mathrm{~W} /\left(\mathrm{m} \cdot{ }^{\circ} \mathrm{C}\right)$, specific heat capacity -1.26 $\mathrm{kJ} /\left(\mathrm{kg} \cdot{ }^{\circ} \mathrm{C}\right)$, density $-100 \mathrm{~kg} / \mathrm{m}^{3}$, compacted fill soil - thermal conductivity coefficient -1.05 $\mathrm{W} /\left(\mathrm{m} \cdot{ }^{\circ} \mathrm{C}\right)$, specific heat $-0.85 \mathrm{~kJ} /\left(\mathrm{kg} \cdot{ }^{\circ} \mathrm{C}\right)$, density $-1500 \mathrm{~kg} / \mathrm{m}^{3}$.

The indicators of heat capacity, thermal conductivity and density of materials were taken from the reference book of the ELCUT software package.

Heating wires in the design model are specified by vertices with a certain heat release power.

The following time parameters were set in the program: integration over time up to 96 hours with a step of solving the problem - 2 hours. After that, the solution to the "rough calculation" problem is launched, which is carried out directly by the ELCUT program, taking into account the heat capacity and thermal conductivity of all construction materials in the design scheme.

\section{Results}

As a result of the data entered into the program, the temperature field in the concrete body of the structure before the start of electrical heating was obtained (Fig. 3).



Fig. 3. Temperature field in the concrete of the foundation structure before the start of electrical heating.

At the stage of "rough calculation", temperature fields in the section of the concrete structure were obtained, which clearly demonstrate (Fig. 4.) uneven electrical heating. After analyzing the results obtained, technological measures were developed to level the 
temperature field, i.e. the layout of the heating wire was changed and the step of winding on the reinforcing cage was changed from $200 \mathrm{~mm}$ to $150 \mathrm{~mm}$.

After adjusting the design model, the temperature field diagrams in the concrete of the structure were obtained, which are shown in Fig. 5, $a-d$. Analyzing the results obtained, it can be noted that after the considered time intervals of electric heating of $6,12,24$ and 72 hours, there is no freezing of concrete in the foundation structure, and a more uniform temperature distribution over the structure section can be observed.

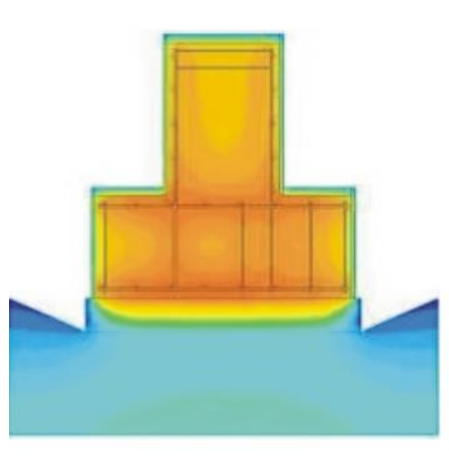

a)

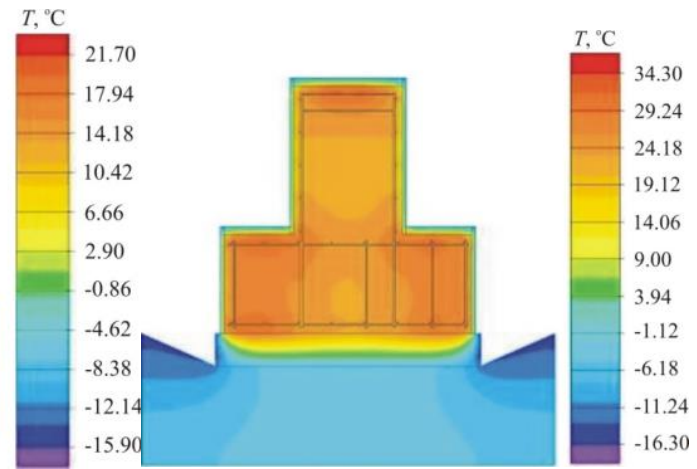

b)

Fig. 4. Temperature field in the concrete of the foundation structure before adjusting the design model after 6 hours (a) and 24 hours (b) of electric heating.



a)

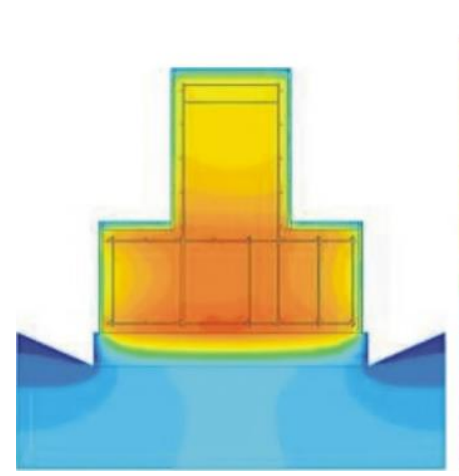

c)
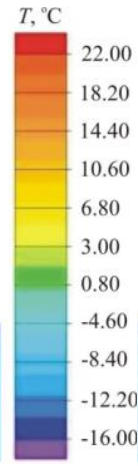

$T,{ }^{\circ} \mathrm{C}$

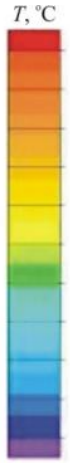
$-16.20$ 1

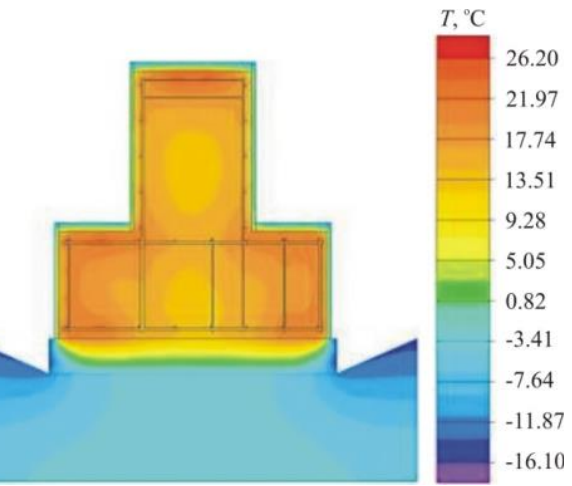

b)

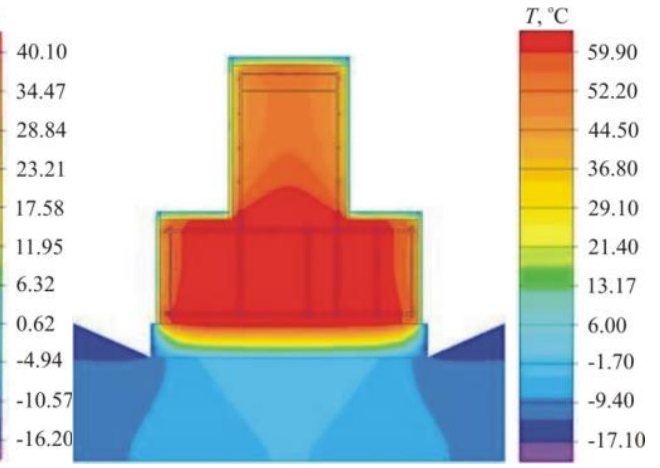

d) 
Fig. 5. Temperature field in the concrete of the foundation structure after adjusting the design model after 6 hours (a), 12 hours (b), 24 hours (c) and 72 hours (d) of electric heating

Further, a refinement calculation was performed using the WinConcret add-in, in which the following parameters were set: concrete class, the temperature coefficient of resistance of the heater is taken into account, and time parameters (duration of curing, heating duration and pre-curing duration) are set, as well as calculation parameters: integration step, step of tasks of the series, after which the calculation itself is started. As a result, an integrated temperature distribution graph and a concrete strength gain graph are obtained.

In the program, the heating time was set, which was 72 hours, the preliminary curing time was 2 hours, and the cooling time was 22 hours. The considered structure was automatically divided into 48 temperature blocks according to the finite element mesh. Each block is assigned a number from 1 to 48 . Block No. 22 is located in the massif (center) of the structure, block No. 1 is the top of the structure, bordering on the insulation, block No. 9 is the bottom of the structure, blocks No. 25,34,36,44 are the edges of the structure (fig. 6).

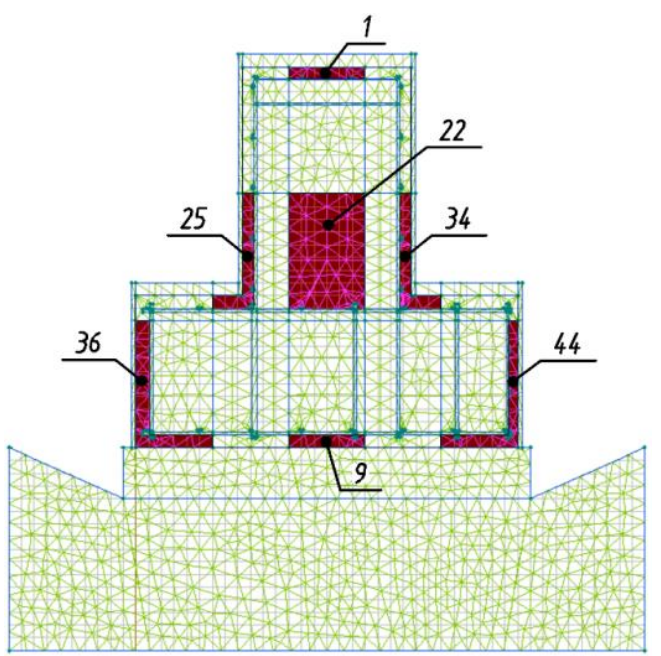

Fig.6. Diagram of the blocks of the foundation structure at the stage of refine calculation

The WinConcret add-in allows obtaining graphs of temperature distribution and strength gain for each block. In the program, data is formatted in tabular and graphical modes. Comparing the data of the graph of the existing heating temperature and the empirical data on the strength gain during temperature cuing, the program produces a graph of the strength gain of concrete as a percentage of the design strength. Below are the integral graphs of temperature and concrete strength gain for the above blocks (Fig. 7-10). 


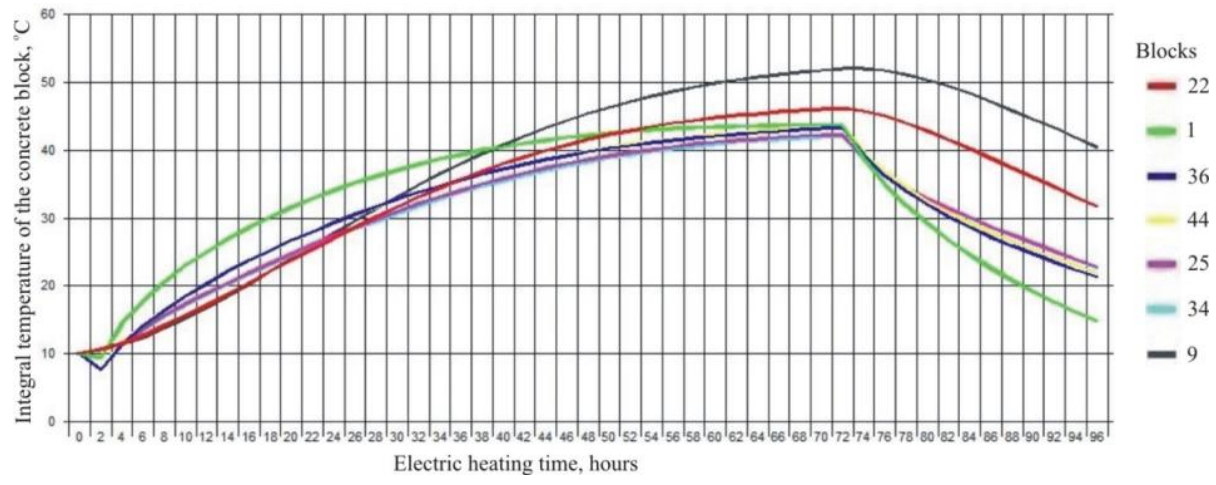

Fig.7. Graph of concrete temperature in different blocks of the foundation structure over time

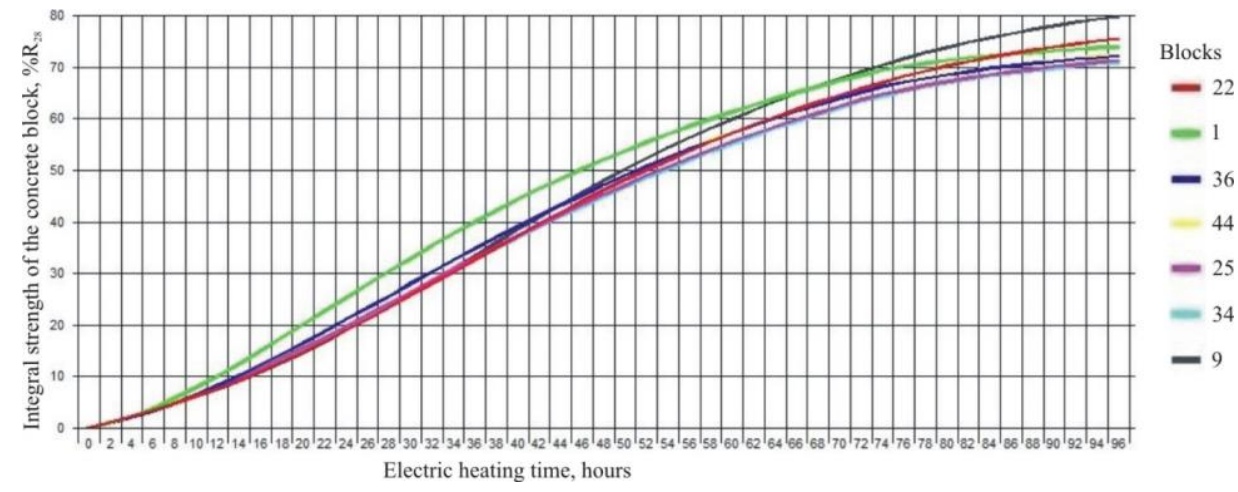

Fig. 8. Graph of concrete strength gain in various blocks of the foundation structure over time



Fig. 9. Graph of the concrete temperature of the entire foundation structure over time 




Fig.10. Graph of concrete strength gain of the entire foundation structure over time

\section{Discussion}

Analyzing the graphs of temperature distribution and strength gain, we can conclude that at the moment of preliminary curing, the concrete in blocks No. 1, 25, 34, 36 and 44 does not drop below $+5^{\circ} \mathrm{C}$. At the moment of electric heating, the maximum temperature is observed in block No. 9 and is $+52.1^{\circ} \mathrm{C}$. This is caused by the fact that it is located in the structure and is not exposed to aggressive environments.

The graph of the integral strength of concrete shows an almost uniform strength gain in each of the blocks.

Considering the integral graphs of temperature and strength over the entire structure (averaged characteristics of all blocks), shown in Fig. 10 and 11, it can be said that concrete gains $70 \%$ of its design strength in 78 hours from the moment it is placed in the formwork. The average maximum concrete temperature is $+46.3^{\circ} \mathrm{C}$.

Having considered the results of numerical simulation, we can conclude that the selected method of electric heating of concrete with insulated heating wires is generally effective.

The development of a flow chart for winter concreting using a heating wire can be carried out on the basis of data obtained as a result of numerical calculations in the ELCUT Pro software package.

\section{Conclusions}

Numerical simulation of thermodynamic processes in the ELCUT software package for electric heating of concrete of a raft foundation with heating wires in winter has been carried out.

This made it possible to assess the temperature fields and the nature of the concrete strength gain not only of the whole structure, but also in its various sections, and to correct the electrical heating parameters.

When simulating electrical heating in the Elcut program, the following parameters were determined:

- layout of the heating wire and the step of winding it onto the reinforcement cage;

- time of electric heating of concrete depending on the outside air temperature;

- strength of concrete at the end of electrical heating.

These calculations made it possible to obtain the most complete picture of the distribution of temperature fields, as well as to make a quick selection of optimal parameters and calculate the time of temperature curing of the concrete of the structure. 
On the basis of the results obtained, practical recommendations are given for choosing an organizational and technological scheme for winter concreting of raft foundations using electric heating with heating wires.

\section{Acknowledgment}

The authors wish to acknowledge the financial support from the Russian Foundation for Basic Research (Grant N 18-08-01025).

\section{References}

1. A.I. Gnyrya, S.V. Korobkov, Concrete work technology in winter: textbook (Publishing house of TSUACE, Tomsk, 2011)

2. D.I. Mokshin, K.S. Gauss, A.V. Rubanov, R.I. Mokshin, Simulation of Curing Processes in Cast-in-place Thin-walled Structure under Different Climatic Conditions, IOP Conf. Series: Materials Science and Engineering 597012035 (2019) doi:10.1088/1757-899X/597/1/012035.

3. M.M. Titov Concreting in winter, Proceedings of universities. Construction 3 (711), 109 (2018)

4. M.N. Ershov, A.A. Lapidus, V.I. Telichenko, Technological processes in construction. Book 5. Technology of monolithic concrete and reinforced concrete: Textbook, (ASV Publishing house, Moscow, 2016)

5. ed. B.A. Krylova, S.A. Ambartsumyan, A.I. Zvezdova, Guidelines for heating concrete in monolithic structures (NIIZhB, Moscow, 2005)

6. P.A. Gnam, R.K. Kiviharju, Winter concreting technologies in Russia, Construction of unique buildings and structures 9(48), 7-25 (2016)

7. Yu.A. Korytov, Winter concreting using heating wires, Mechanization in construction 3, 14-20 (2010)

8. A.K. Sysoev, Winter concreting technology using flexible heating wires, Engineering journal of Don 27(4) 279 (2013)

9. G. Fedorova, V. Mestnikov, O. Matveeva, E. Nikolayev, Features of high-strength concrete creation for concreting of monolithic constructions in the far north conditions, Procedia engineering 57, 264-269 (2013)

10. A.B. Valt, A.A. Ovchinnikov, Methods of heat treatment of concrete during the construction of monolithic structures, Izvestiya of the Kaliningrad State Technical University 13, 109-112 (2008).

11. M.O. Dudin, N.I. Vatin, Yu.G. Barabanshchikov, Modeling of concrete strength gain in the ELCUT program during heating of monolithic structures with a wire, Magazine of Civil Engineering 2, 33-45 (2015)

12. V.V. Molodin, Controlled temperature regimes of concrete curing - a way to increase the efficiency of concrete work, Polzunovsky Vestnik 4-1, 149-153 (2013)

13. V.V. Dombrovskii, 2018 ELCUT, a program for engineering analysis and twodimensional finite element modeling (OOO "Tor", Saint-Petersburg, 2018) www.elcut.ru/ 
14. E.B. Tolochnaya, M.M. Titov, Numerical modeling of thermophysical processes in the technology of winter concreting of a precast-monolithic frame of a building, Proceedings of universities. Construction 11-12, 54-61 (2012)

15. O.A. Ostarkova, R.V. Oniskovets, Modeling the heating of the floor slab with heating wires in the Far North using the ELCUT software, Actual problems of the humanities and natural sciences 5-1, 60-68 (2017)

16. Dugersuren Enkhbaatar, M.M. Titov, Improving the technological design of winter concreting in modern construction, Vestnik of TSUACE 3, 159-168 (2018) doi: 10.31675/1607-1859-2018-20-3-159-168.

17. N.N. Zhurov, S.V. Komissarov, System of temperature and strength control of concrete at an early age, Vestnik MGSU 4(5), 296-300 (2010)

18. N.N. Zhurov, S.V. Komissarov, System of temperature and strength control of concrete at an early age, Vestnik MGSU 4(5) 296-300 (2010)

19. M.V. Komarinsky, R.V. Oniskovets, Simulation modeling of winter concreting of wall structures Actual problems of the humanities and natural sciences 7, 18-31 (2017)

20. L.V. Zinevich, Application of numerical modeling in the design of heating technology and concrete curing of monolithic structures, Magazine of Civil Engineering 2, 24-28 (2011) 